\title{
Functional Bladder and Bowel Problems: How to Treat Them?
}

\section{Bakker $\mathrm{E}^{*}$, Segers $\mathrm{N}^{2}$, Claes $\mathrm{M}^{2}$, Palinckx A $\mathrm{A}^{2}$, Bael $\mathrm{A}^{2}$}

${ }^{1}$ HE L de Vinci-IES Parnasse-Deux Alice -Unité de Recherche-Avenue Mounier 84- B-1200 Bruxelles

${ }^{2}$ ZNA Kon Paola Kinderziekenhuis- Lindedreef 1 -B-2020 Antwerpen

\section{Abstract}

In order to achieve urinary and faecal continence an efficient control on both systems is necessary, which means equilibrium between the two important phases of each system: storage and emptying. This implicates not only control of the pelvic floor muscles (contraction and relaxation) but also a correct interpretation of the sensorial information during both functional alternative phases leading to social acceptable responses by "automatic" and voluntary procedures. Those automatic and voluntary responses are part of a learning process.

\section{Introduction}

Efficient control of urinary and bowel function in children means equilibrium between the two important phases of each system: storage and emptying. This implicates not only correct interpretation of the sensorial information from the bladder and the bowel, but also an adequate response to this information leading to social acceptable behavior by automatic and voluntary procedures.

The whole process requires perfect co-ordination of smoothand striated muscles of the outflow region of the little pelvis and is regulated by complex neural control systems at different levels of our central nervous system (CNS). Publications in healthy adults on the activity of the brain during bladder filling showed cortical activity inhibiting the bladder from the beginning on, allowing filling at low pressure without detrusor contractions. This inhibitory cortical activity during filling is strongly diminished in adults suffering from urgency with or without leakages, symptoms caused by uninhibited contractions of the detrusor [1]. Unfortunately, at our knowledge nothing has been published on cortical activity during bladder filling in children, but it seems logical that a similar mechanism plays a role in urgency related symptoms in this population.

In order to achieve continence, the child must first master a correct interpretation of bladder and bowel fullness, and then must control the moment of emptying at a social acceptable time, thus the ability to postpone a miction/defecation by contracting PFM. Finally he must be able to initiate the emptying phase by abolishing central inhibition and relaxing pelvic floor muscles (PFM). This whole integration is accepted to be part of a learning process and requires a good control of the PFM, which means not only contraction but also relaxation.

Contraction of PFM will increase urethral closure pressure, inhibit the detrusor thanks to a sacral reflex, close the anorectal and rectorectal angle and increase external anal sphincter (EAS) pressure [2]. At the other hand relaxation will decrease urethral closure pressure, open the anorectal angle and EAS allowing complete emptying of bladder and bowel. Clinically we observe most of the time nonrelaxing PFM in children with urinary and/or bowel dysfunctions.

PFM are activated by 3 distinct pathways: the somatic motor system (voluntary command and axial movements), the emotional motor system (anticipatory postural adjustments and behaviour) and by direct projections on the Nucleus of Onuff from the Pontine Micturition Center [3].

Int J Phys Ther Rehab

ISSN: 2455-7498

\author{
Publication History: \\ Received: January 03, 2018 \\ Accepted: March 18, 2018 \\ Published: March 20, 2018
}

Keywords:

Overactive bladder, Urgency, constipation, Nocturnal enuresis

This rather complex activation of PFM implicates that high tone of PFM or a lack of relaxation is not necessarily linked to voluntary contraction, but can be caused by an automatic response of those muscles to

1. Postural perturbations (musculoskeletal dysfunctions of the thoraco-abdomino-lumbopelvic region, inadequate toiletsitting,....)

2. Changes in intra-abdominal pressure during the emptying phase (straining)

3. Activation through the Pontine Micturition Center, etc.

This reveals the need to have a global approach during our treatment, considering exclusively the voluntary activation of PFM is a mistake in our therapeutically approach.

The similar and mostly shared nerve and blood supply of the bladder and the bowel leads to a very strong interaction between them. Koff proposed in 1998 the concept of "dysfunctional eliminating" renamed as Bladder/Bowel Dysfunction (BBD) by the ICCS in 2012 [4,5]. This explains the necessity to consider the two systems together, but for a better understanding we will start to analyze each item separately [6].

\section{Lower Urinary Tract Dysfunctions}

The infant bladder has for a long time been accepted to be overactive and to empty automatically at regular intervals through simple spinal reflexes and without any control of higher centres $[7,8]$. Development was believed to be an exclusively maturational process, normally functional at the age of 4 years [9]. It was only in 1999 that several authors pointed out spinal micturition pathways which were influenced by behaviour and/or arousal, leading to dyssynergic voiding patterns with incomplete emptying in infants. They concluded that voiding with incomplete coordination between detrusor contraction and sphincter relaxation could be normal [10]. These influences have since been confirmed by other urodynamic studies revealing the presence of more complex mechanisms during filling and voiding than has earlier been thought [11]. Spinal micturition pathways, involving a complex integration of neural pathways at both peripheral "Corresponding Author: Dr. Bakker E, HE L de Vinci- IES Parnasse-Deux Alice Unité de Recherche - Bruxelles; E-mail: els.bakker@vinci.be

Citation: Bakker E, Segers N, Claes M, Palinckx A, Bael A (2018) Functional Bladder and Bowel Problems: How to Treat Them?. Int J Phys Ther Rehab 4: 145. doi: https://doi.org/10.15344/2455-7498/2018/145

Copyright: (c) 2018 Bakker et al. This is an open-access article distributed under the terms of the Creative Commons Attribution License, which permits unrestricted use, distribution, and reproduction in any medium, provided the original author and source are credited. 
Citation: Bakker E, Segers N, Claes M, Palinckx A, Bael A, et al. (2018) Functional Bladder and Bowel Problems: How to Treat Them?. Int J Phys Ther Rehab 4: 145. doi: https://doi.org/10.15344/2455-7498/2018/145

Page 2 of 6

and central levels, are influenced by behaviour and/or arousal: e.g. micturition never occurs during quiet sleep: there is a cortical arousal in response to full bladder even in new-born infants $[12,13]$.

\section{Normal function of the LUT requires}

1. Bladder filling with little or no changes in pressure

2. Correct interpretation of bladder filling,

3. Postponement of the voiding by voluntary PFM contraction,

4. Initiation of the voiding by abolishing central inhibition of the bladder and PFM relaxation,

5. Complete bladder emptying within a normal time span in absence of any obstruction.

Consequently, functional urinary pathophysiology can be divided into abnormalities during filling or during emptying phases, though dysfunction can occur during both simultaneously. Symptoms of these dysfunctions are urgency, incontinence, urinary tract infections, and can occur during day and/or night time [6].

\section{Bladder filling phase}

\section{Overactive bladder (OAB)}

The first descriptions of non-neurological detrusor dysfunctions in patients with severe disease date from Beer in 1915 [14]. He described disharmony between sphincter and detrusor and postulated it was caused by an occult neurological disorder. Further reports on this condition did not appear until 1973, when Hinman described a small group of children with urgency, uncoordinated micturition, and recurrent Urinary Tract Infection (RUTI) without neurological or obstructive diseases. It was thought to be a behavioural disorder. Its reversal by biofeedback and hypnosis gave an argument in favour of the behavioural nature [15].

Different terminology has since been used in the pathophysiology of filling: uninhibited bladder, infantile bladder, irritable bladder, spastic bladder, reflex bladder. In the ICS standardisation of the terminology of lower urinary tract dysfunction the term "detrusor instability", adopted as first used by Bates in 1970, was reserved for an involuntary phasic detrusor contraction of any pressure during the filling phase while the patient is trying to inhibit micturition [16,17]. In patients with relevant neuropathy this was called "detrusor hyperreflexia". In 2002 the ICS standardisation and terminology has introduced the term overactive bladder $(\mathrm{OAB})$, defined as a urodynamic observation characterised by involuntarily detrusor contractions during the filling phase which may be spontaneous or provoked, and can be qualified according to the cause in neurogenic- or idiopathic detrusor overactivity.

Clinically $\mathrm{OAB}$ is characterised by urgency (formerly urge syndrome or urgency syndrome). Urgency is defined as the complaint of a sudden compelling desire to pass urine, which is difficult or impossible to defer in absence of a proven infection or other obvious pathology [18]. This condition may lead to leakages (urge- incontinence), which is the complaint of involuntary leakage accompanied by or immediately preceded by urgency $[19,20]$.

Urgency is common in children with incontinence and usually peaks in the afternoon. Children with urge presents significantly more RUTI compared to healthy children [21]. It can have a nocturnal component, which may or may not wake the child. The wetting at night in that condition is caused by the same dysfunction as its daytime's component.

The exact causes of the development of $\mathrm{OAB}$ in children are yet unclear. It has been believed that the uninhibited bladder contractions are exclusively a consequence of a retardation of the maturation of the reticulospinal cords and the inhibition centres in the cerebral cortex. The influence of toilet training on the presence of $\mathrm{OAB}$ at age 10 to 14 years and its reversal by timed drinking and voiding gave an argument in favour of a behavioural component [22].

To minimise wetting the child with urgency will use PFM contraction. He/she may even add external compression to the urethra, such as sitting on the point of a chair, pushing the heel against the urethra [23]. This repetitive contraction to avoid leakages will "overtrain" the PFM, leading to hypertonic and non-relaxing PFM, creating a functional outlet obstruction during voiding. The dysfunctional voiding will, in turn, reinforce the detrusor muscle leading to thickened bladder wall and small bladder capacity for the age of the child, maintaining the filling phase dysfunction [6].

\section{Abnormal bladder sensation}

Bladder sensation may be increased (an early desire to void at low volume for age), reduced (diminished sensation during bladder filling) or absent. Bladder sensation is difficult to evaluate in children, and can only be used in toilet trained cooperative children. It can be judged by three defined points noted during cystometry and evaluated in relation to bladder volume at that moment [24]. Children suffering from $\mathrm{OAB}$ often have small bladder capacity for their age, while children postponing toilet visit (linked to e.g. dirty closets at school) may develop a large, lazy bladder [25].

\section{Incompetent urethral closing mechanism}

Very exceptional in children without neurological diseases, and therefore not discussed in this paper.

\section{Bladder emptying phase}

\section{Dysfunctional voiding}

Normal emptying of the bladder requires a complete relaxation of the PFM, activation of those muscles during voiding will lead to a weak or intermittent urine flow, and incapacity to empty correctly the bladder, in turn leading to the presence of a post mictional residu (PMR). Shaikh et al. found a significant relation between dysfunctional voiding (DV) and occurrence of RUTI [26].

Different patterns of dysfunctional voiding have been described, all with PFM overactivity during voiding as common denominator. The patterns range from staccato voiding, to fractionate voiding to hypo- or acontractile bladder (formerly lazy bladder) with incomplete pathogenesis of these disorders easy to understand [27].

Staccato voiding occurs in case the PFM no longer relax completely. This rhythmic voiding pattern is caused by periodic bursts of pelvic floor activity during voiding; resulting in dips in the urine flow rate coinciding with high detrusor pressure. The PFM contractions can be triggered by a flow rate above a certain threshold. As soon as this contraction has reduced the flow rate, the pelvic floor relaxes again 
Citation: Bakker E, Segers N, Claes M, Palinckx A, Bael A, et al. (2018) Functional Bladder and Bowel Problems: How to Treat Them?. Int J Phys Ther Rehab 4: 145. doi: https://doi.org/10.15344/2455-7498/2018/145

Page 3 of 6

and the flow rate regains the threshold. Flow time is prolonged and emptying may not be complete, increasing the child's risk for developing UTI.

Fractionated voiding is characterised by incomplete and infrequent voiding, with micturition in several separate fractions, due to voluntary or automatically induced contractions of the PFM, and possibly caused by augmented pressure of the abdomen.

The most important problem in these children is their inability to relax PFM during the mictions. This inability to relax might be caused by the continuous use of PFM contraction as emergency brake to prevent leakage's in $\mathrm{OAB}$, but also to an inappropriate activation of the PFM, either voluntary or automatically (eg instability, straining, pain) [6].

\section{Detrusor underactivity}

Detrusor underactivity, the hypo- or acontractile bladder, is defined as a contraction of reduced strength and/or duration, resulting in prolonged bladder emptying and/or failure to achieve complete bladder emptying. The most extreme form is an acontractile detrusor. This pattern in children was recognised in 1962 by Luca.

A comprehensible mechanism of this would be the voluntary, repeated postponement of the voiding, which can also lead to chronic overactivity of the pelvic floor, with overdistension of the bladder and loss of perception of bladder filling. Gradually the bladder will lose its capacity to contract and the voiding consists of several inadequate detrusor contractions, each with his own flow. Abdominal pressure is often used to shorten the flow time and increase the flow rate. These children will present incomplete voiding on abdominal pressure with high post mictional residu, inducing RUTI. Wetting in these cases is usually secondary to overflow incontinence.

However, the fact that children with hypo- or acontractile bladders usually tend to be younger than those with $\mathrm{OAB}$ and/or dysfunctional voiding defavorizes this hypothesis.

\section{Bedwetting}

Nighttime wetting is a very bothersome condition for children and parents. A study in 4332 Belgian children aged from 10-14 years showed clearly that night-time wetting is the most important reason to seak for professional help, where daytime wetting tends to be kept in the dark.

In many cases nighttime wetting or nocturnal enuresis (NE) is associated with functional problems and will then be referred to as non-monosymptomatic NE. Only Monosymptomatic NE (MNE) is defined as nighttime wetting without any functional disorder, and concerns a minority of all bedwetting children [28]. It seems logical to restore first the normal bladder and bowel function during daytime, before trying to solve the nighttime symptoms [29].

The association between nocturnal enuresis and sleep remains a point of discussion. In the past, it was assumed that nocturnal enuresis was associated with a deep sleep and a high arousal threshold [30]. Although there was never hard clinical evidence for this, it was rather based on parent's reports. More recent studies suggest an opposite theory, indicating that nocturnal enuresis is associated with a light and frequently interrupted sleep, leading to an inability to wake up to void. [30-32] Dhondt et al. also found an association between monosymptomatic nocturnal enuresis with nocturnal polyuria and Periodic Limb Movement Disorder [33]. PLMD is a sleep disorder where the patient moves the lower limbs involuntary during sleep and is unaware of this movement. The disorder is caused by an autonomic dysfunction and leads to cortical arousals and sleep. [34]

In conclusion, nowadays we believe that nocturnal enuresis leads to sleep fragmentation as a result of cortical arousals due to voiding, which in turn leads to a higher arousal threshold. In addition, there's also an association between nocturnal polyuria and sleep disorders.

\section{Bowel Dysfunction}

Functional gastrointestinal dysfunctions (FGID) in children are common and defined by the Rome IV criteria [35]. Constipation is the most frequent complaint, and is defined in toddlers over 4 years as less than 2 defecations a week, painful defecation with straining and presence of stool in the rectum occurring on a regular basis without any organic cause. The constipation can be associated with soiling, which is defined as the involuntary seepage of formed, semi-formed or liquid stool into the child's underwear in the presence of idiopathic (functional) constipation in a child after the age of 4 years resulting in staining of underwear.

Functional constipation, with or without soiling is often associated with urinary urgency. The high PFM tone present in urge syndrome and in dysfunctional voiding, as a result of defence against urine-loss, might contribute to the occurrence of constipation by closing the anorectal angle and a non-relaxating or even contracting EAS. [36-39].

This explains the link between constipation, OAB and UTI described as by O'Regan in 1985, and confirmed by Romanczuk and Korczawski in 1993, who revealed a high percentage of LUT-problems in hospitalised children for chronic constipation [40,41].

\section{Bowel filling phase : Abnormal sensation}

The overtraining of pelvic floor muscles to withhold stool or counteract urgency, causes faecal impaction, causing pain during the defaecation, leading to a paradoxal contraction of the sphincter and incomplete emptying of the bowel [42]. This leads to chronic distension, decreased ano-rectal sensibility, more faecal impaction, more pain and finally involuntary stool loss. Indeed, infants and toddlers with constipation usually have a history of infrequent, hard and painful bowel movements, often accompanied by screaming and stool-holding manoeuvres [43].

Non-relaxation of the PFM will not allow the opening of the anorectal angle and EAS leading to postponement of the next defecation, delay of eliminating stool, hard stools and eventually incomplete emptying.

A paradoxal contraction of the PFM is defined as contraction of the puborectalis muscle or/and EAS during defecation [44-46]. This contraction can be voluntary in answer to anal pain, or fear for pain, caused by hard stools or previous anal injuries. This paradoxal contraction can be involuntary in answer to an inappropriate position, for e.g. dangling legs while using regular toilets rather than a potty creating disequilibria with postural perturbation, triggering automatic contractions of the PFM [47-50]. 
Citation: Bakker E, Segers N, Claes M, Palinckx A, Bael A, et al. (2018) Functional Bladder and Bowel Problems: How to Treat Them?. Int J Phys Ther Rehab 4: 145. doi: https://doi.org/10.15344/2455-7498/2018/145

Page 4 of 6

\section{Explanation and demystification}

The first step is a dialogue between the child and the therapist, about normal bladder/bowel function. It is important to get the child interested in its own condition. An essential part of this is to explain, using all images which can help.

\section{Diaries [51-53]}

Voiding and drinking diary: to promote a normal bladder work schedule, a $\mid$ The defecation diary is used to teach the child to deal consciously with his bladder regime is often applied. This implies voluntary initiation of voiding bowel problem.

on predetermined times with 1-3 hours intervals, and without previous These charts are used to teach the child how to obtain an appropriate liquid urge, in order to practise voluntary control over the bladder. Another goal intake and a regular toilet visit. The schedule is adapted after evaluation at is to regain a normal rhythm of bladder emptying.

Frequency/volume charts are filled in by the child, scheduled to follow the daily life of the child. Children with urge start with shorter intervals, gradually increasing them as soon as the urgency attacks disappear. Children with a hypo- or acontractile bladder have to learn to decrease the intervals every consultation

Relaxation of Pelvic Floor Muscles [53-57]

In children pelvic floor muscles almost never fail as emergency brake, except sometimes during imperative urge, or during uncontrolled laughing. However, the most common problem occurs in children when they are unable to relax the pelvic floor during voiding. In some cases, instructions and practise can remedy this problem, but in the more severe cases the treatment should focus specifically on the pelvic floor. Several programs exist with pelvic floor exercises and perception practice, tailored to suit children. A prospective evaluation reported a success rate of more than $80 \%$ in 42 girls with a history of recurrent UTI and urodynamically documented bladder sphincter dysfunction. The studies describe physiotherapy exercises in an excellent way and show definite improvement of signs and symptoms. Controlled studies on physiotherapy alone are still missing, as programs described are always compound packages of pelvic floor exercises, biofeedback and behavioural therapy.

Biofeedback $[51,54,56,7,58-64]$

Implies perception of filling phase or emptying phase. This is achieved through monitoring of these activites, in a way which is easy to follow by the child. The feedback loop enables the child to influence the process, provided cognitive capacities are developed normally. Numerous studies reported on the efficacy of this treatment in children

Flow patterns will teach the child how to relax the pelvic floor during the $\quad$ Inflatable Balloons are used to learn correct perception and emptying voiding. The child sits on a toilet with a flow transducer, watching flow curve and EMG on-line on a computer display, trying to empty completely in one relaxed voiding.

\section{Neuromodulation [65-68]}

Transcutaneous and percutaneous neuromodulation delivered over either the sacral region, anogenital region or peroneal region of the ankle, has proven a useful adjunctive treatment in children with bladder overactivity. Intravesically stimulation can potentially improve detrusor contractility and enhance bladder emptying. Recent studies indicate its effectiveness in children with severe dysfunctional elimination syndrome refractory to maximum medical treatment.

Clearly neuromodulation in children warrants larger, controlled and randomized studies, including studies about its use as first-line intervention and in children with combined bladder and bowel dysfunction.

Reported changes on bladder function with neuromodulation include: significantly increased bladder capacity, decreased severity of urgency, improved continence, and decreased frequency of urinary tract infection. Significant improvement in urodynamic parameters of bladder compliance, number of involuntary contractions, and bladder volume at first detrusor contraction have also been noted.

Level of evidence: 4

Grade of recommendation D

Rules for application at home $[53,63]$

After evaluation of fluid intake and eating habits, rules for a fixed intake are made, including reminders, designed for use between the visits to the

hospital. Information and rules for application at home can be used:

1. every time that I feel that my bladder wants to pee, I go immediately to the toilet

2. during voiding I keep my stomach asleep, I do not strain but count, sing or whistle

3. after voiding I do not run away from the toilet immediately, but I count quietly up to five before wiping off

4. Every time I go to the toilet I look if my pants are

5. still dry. If they are wet I have to change them.

Toilet Posture [53,69,70]

Children are advised to void sitting down on the toilet, with a small bench $\quad$ A proper toilet posture for defaecation implies that the legs are spread and to support their feet. Thighs have to be spread; the back has to be hold straight, and tilted slightly forward.
Drink water, pay attention to your diet (a lot of fibres, vegetables and fruit) Sit 3 times a day on the toilet after each meal and I always pay attention to posture on the toilet and think of the relaxation exercises of the pelvic floor during straining the feet supported, the knees should be higher than the hips. The back is slightly bent forward, which is the optimal position to reach perfect relaxation of the pelvic floor during straining. In children who can not reach the floor with their feet a small bench or support is placed under the feet. 
Citation: Bakker E, Segers N, Claes M, Palinckx A, Bael A, et al. (2018) Functional Bladder and Bowel Problems: How to Treat Them?. Int J Phys Ther Rehab 4: 145. doi: https://doi.org/10.15344/2455-7498/2018/145

Page 5 of 6

Finally, for a variety of reasons, the toilet training process itself can be a primary cause of stool-withholding behaviour and constipation if toddlers in training withhold stools as response to excessive parental pressure.

\section{Therapy}

Although medication with anticholinergics for $\mathrm{OAB}$, antibiotics for treatment or prophylaxis for UTI or laxatives for treatment of concomitant constipation are still very popular, conservative therapy has gained a lot of attention during the last years.

This therapy, used in the rehabilitation of dysfunctional bladder and bowel, is a combination of cognitive, behavioural and physical therapy methods. The programs are based on a careful evaluation of bladder and bowel function. The aim of this training is to normalise the whole voiding and defecation pattern and prevent further functional disturbances. Function should be viewed as an integrated concept, from the filling to the emptying phase.

In the table beyond you will find a proposition for a systematic approach for urinary (left colomn) and faecal (right colomn) dysfunctions.

\section{Conclusion}

The association between bladder and bowel dysfunction has been described in many reports, but the exact pathophysiology remains unclear, although the anatomical proximity of bladder and bowel, and the identical innervations of the urethra and the anal sphincter make it is tempting to conceptualise that dysfunction can occur in both systems simultaneously. Until yet the exact starting point of the dysfunctions is not established, probably it can start from different stations at the time. Whether PFM dysfunctions are leading to non-neurological bladder and bowel dysfunctions (NNBSD) or the inverse is until yet not clear but it is well accepted that NNBSD plays an important role in urological and bowel symptoms, leading to symptoms as urinary and/or faecal incontinence, frequency, urge or reduced autonomy for bowel movements and recurrent urinary infections [54].

It therefore is very important to consider global storage and emptying functions of the small pelvis and to treat both at the same time. Many authors report resolution of urinary symptoms in treating constipation, and vice versa $[40,63,71,72]$. Actually, the tendency is to first treat bowel problems, before the urinary symptoms.

Standardisation and definitions are used in this article as approved by the International Children's Continence Society (ICCS) in 1998, adapted to the new terminology 2002 of the ICS (International Continence Society).

\section{Competing Interests}

The authors declare that they have no competing interests.

\section{References}

1. Fowler CJ, Griffiths D, de Groat WC (2008) The neural control of micturition. Nat revue neuroscience 9: 453-466.

2. de Groat WC, Ryall RW (1969) Reflexes to sacral parasympathetic neurons concerned with micturition in the cat. J Physiol 200: 87-108.
3. Holstege G (1992) The Emotional Motor System. Eur J Morphol 30: 67-69.

4. Koff SA, Wagner TT, Jayanthi VR (1998) The relationship among dysfunctional elimination syndromes, primary vesicoureteral reflux and urinary tract infections in children J Urol 160: 1019-1022.

5. ICCS in 2012

6. Bakker E, de Vinci HEL (2013) Enuresis, dysuria, encopresis...could the pelvic floor be the link? Adv in Phys Ther J 1: 32-46.

7. Bauer SB, Retik AB, Colodny AH, Hallett M, Khoshbin S, et al. (1980) The unstable bladder in childhood. Urol Clin North Am 7: 321-336.

8. Hjalmas K (1988) Urodynamics in normal infants and children. Scand J Uro Nephrol Suppl 114: 20-27

9. Doleys DM, Dolce JJ (1982) Toilet training and enuresis. Pediatr Clin North Am 29: 297-313.

10. Sillen U, Hellstrom AL, Holmdahl G, Solsnes $E$ (1999) The voiding pattern in infants with dilating reflux. BJU Int 83: 83-87.

11. Gladh G, Persson D, Mattsson S, Lindstrom S (2000) Voiding pattern in healthy newborns. Neurourol Urodyn 19: 177-184.

12. Wille S (1994) Nocturnal enuresis: sleep disturbance and behavioural patterns. Acta Paediatr 83: 772-774.

13. Neveus T, Hetta J, Cnattingius S, Tuvemo T, Lackgren G, et al. (1999) Depth of sleep and sleep habits among enuretic and incontinent children. Acta Paediatr 88: 748-752.

14. Beer E (1915) Chronic retention of urine in children. JAMA 65: 1709

15. Hinman F, Baumann FW (1973) Vesical and ureteral damage from voiding dyfunction in boys without neurologic or obstructive disease. J Urol 109: 727-732.

16. Bates CP, Whiteside CG, Turner-Warwick R (1970) Synchronous cinepressure-flow-cysto-urethrography with special reference to stress and urge incontinence. Br J Urol 42: 714-723.

17. Standardisation of the terminology of function of the lower urinary tract (1976) Incontinence, cystometry, ureteral profile, units of measurement (author's transl)] J Urol Nephrol 82: 429-36.

18. Abrams P, Cardozo L, Fall M, Griffiths D, Rosier $P$, et al. (2002) The standardisation of terminology of lower urinary tract function: report from the standardisation Sub-committee of the International Continence Society. Neurourol Urodyn 21: 167-78

19. Van Gool JD, Van Wijk AA, de Jong TP (1989) The urge syndrome in children Acta Urol Belg 57: 559-562.

20. van Gool J, de Jonge G (1989) All children referred with recurrent UTI and clinically manifest. NNBSD Arch Dis Child 64: 1629-1634.

21. Bakker E, van Gool J, van Sprundel M, Van Der Auwera J, Wyndaele JJ, et al. (2002) Risk factors for urinary tract infection in a population of 4332 Belgian schoolchildren aged between 10-14 years. Eur J Paediatr 163: 234-238.

22. Bakker E, van Gool J, van Sprundel M, Van Der Auwera J, Wyndaele JJ, et al. (2002) Results of a questionnaire evaluating the effects of different methods of toilet training on achieving bladder control. BJU Int 90: 456-461.

23. Wald A, Chandra M, Chiponis D and Gabel S (1987) Anorectal function and continence mechanisms in childhood encopresis. J Pediatr Gastroenterol Nutr 6: 554-558.

24. Breugelmans AL, Wyndaele JJ (1992) Urodynamic findings in patients below 12 years old with different clinical types of enuresis. Acta Urol Belg 60: 6571.

25. Hellstrom AL (2000) Influence of potty training habits on dysfunctiona bladder in children Lancet 356: 1787

26. Shaikh N, Abedin S, Docimo SG (2005) Can ultrasonography or uroflowmetry predict which children with voiding dysfunction will have recurrent urinary tract infections? J Urol 174: 1620-1622.

27. van Gool J (1996) Non-neuropathic bladder-sphincter dysfunction: a complex of bladder/sphincter dysfunction, UTI and VUR Acta Urol Belg 63: 27-33.

28. Bakker (2002) Voiding habits and wetting in a population of 4332 Belgian children aged between 10-14 years. Scand J Urol and Nephrol.

29. Kalo BB, Bella H (1996) Enuresis: prevalence and associated factors among primary school children in Saudi Arabia. Acta Paediatr 85: 1217-22.

30. Wolfish NM, Pivik RT, Busby KA (1997) Elevated sleep arousal thresholds in enuretic boys: clinical implications. Acta Paediatr 86: 381-384. 
Citation: Bakker E, Segers N, Claes M, Palinckx A, Bael A, et al. (2018) Functional Bladder and Bowel Problems: How to Treat Them?. Int J Phys Ther Rehab 4: 145. doi: https://doi.org/10.15344/2455-7498/2018/145

Page 6 of 6

31. Azevedo Soster L, Alves R, Fagundes SN, Koch VHK, Bruni O, et al. (2016) Sleep disturbances associated with sleep enuresis: a questionnaire study. Eur J Paediatr Neurol 20: 282-285.

32. Cohen-Zrubavel V, Kushnir B, Kushnir J, Sadeh A (2011) Sleep and sleepiness in children with nocturnal enuresis. Sleep 34: 191-194.

33. Dhondt K, Baert E, Van Herzeele C, Raes A, Groen LA, et al. (2014) Sleep fragmentation and increased periodic limb movements are more common in children with NE. Acta Paediatr 103: 268-272.

34. Miglis M (2016) Autonomic dysfunction in primary sleep disorders. Sleep Med 19: 40-49.

35. Benninga MA, Faure C, Hyman PE, St James Roberts I, Schechter NL, et al. (2016) Childhood functional gastro-intestinal disorders: neonate/toddler. Gastroenterology 150: 1443-1455.

36. Wan J, Kaplinsky R, Greenfield S (1995) Toilet habits of children evaluated for urinary tract infection. J Urol 154: 797-9.

37. Blethyn AJ, Jenkins HR, Roberts R, Verrier Jones K (1995) Radiological evidence of constipation in urinary tract infection. Arch Dis Child 73: 534

38. Loening-Baucke V (1997) Urinary incontinence and urinary tract infection and their resolution with treatment of constipation in childhood. Pediatrics 100: 228-232.

39. De Paepe H, Renson C, Van Laecke E, Raes A, Vande Walle J, et al. (2000) Pelvic-floor therapy and toilet training in young children with dysfunctional voiding and obstipation. BJU Int 85: 889-893.

40. O'Regan S, Yazbeck S, Schick E (1985) Constipation, bladder instability, urinary tract infection syndrome. Clin Nephrol 23: 152-154.

41. Romanczuk W, Korczawski R (1993) Chronic constipation: a cause of recurrent urinary tract infections. Turk J Pediatr 35: 181-188.

42. Loening-Baucke VA (1987) Factors responsible for persistence of childhood constipation. J Pediatr Gastroenterol Nutr 6: 915-922.

43. Loening-Baucke VA, Younoszai MK (1982) Abnormal and sphincter response in chronically constipated children. J Pediatr 100: 213-218.

44. Keren S, Wagner Y, Heldenberg D, Golan M (1988) Studies of manometric abnormalities of the rectoanal region during defaecation in constipated and soiling children: Modification through biofeedback therapy. Am Gastroenterol 83: 827-831.

45. Wald A, Chandra M, Chiponis D, Gabel S (1987) Anorectal function and continence mechanisms in childhood encopresis. J Pediatr Gastroentero Nutr 6: 554-558.

46. Wasserman I (1964) Puborectalis syndrome. Dis Colon Rectum 7: 87-89.

47. Smith MD, Coppieters MW, Hodges PW (2007) Postural response of the $\mathrm{PF}$ and abdominal muscles in women with stress urinary incontinence. Neurourol and Urodyn 26: 377-385.

48. Steenstrup B, Giralte F, Bakker E, Grise P (2014) Evaluation de l'activité électromyographique des MPP pendant des exercices posturaux à l'aide du jeu vidéo virtuel Wii Fit Plus (C. Prog Urol 24: 1099-1105.

49. Issenman RM, Filmer RB, Gorski PA (1999) A review of bowel and bladder control development in children: how gastrointestinal and urologic conditions relate to problems in toilet training. Pediatrics 103: 1346-1352.

50. Christophersen ER (1991) Toileting problems in children. Pediatr Ann 20: 240-244

51. Hellstrom $A L$, Hjalmas $K$ and Jodal $U$ (1987) Rehabilitation of the dysfunctional bladder in children: method and 3-year followup. J Urol 138: 847-849.

52. Hellstrom AL (1992) Urotherapy in children with dysfunctional bladder. Scand J Urol Nephrol Suppl 141: 106-107.

53. Hoebeke P, Renson C, De Schrijver L, Leenaerts E, Schoenaers A, et al. (2011) Prospective evaluation of clinical voiding reeducation or voiding school of LUT conditions in children. J Urol 186: 648-654.

54. Hoebeke P, Vande Walle J, Theunis M, De Paepe H, Oosterlinck W, et al. (1996) Outpatient pelvic-floor therapy in girls with daytime incontinence and dysfunctional voiding Urology. 48: 923-927.

55. McKenna PH, Herndon CD, Connery S, Ferrer FA (1999) Pelvic floor muscle retraining for pediatric voiding dysfunction using interactive compute games. J Urol 162: 1056-1062.

56. Herndon CD, Decambre $M$, McKenna PH (2001) Interactive compute games for treatment of pelvic floor dysfunction. J Urol 166: 1893-1898.
57. De Paepe H, Hoebeke P, Renson C, Van Laecke E, Raes A, et al. (1998) Pelvic-floor therapy in girls with recurrent urinary tract infections and dysfunctional voiding. Br J Urol Suppl 3: 109-113.

58. Jerkins CR, Noe HN, Vaughn WR, Robert E (1987) Biofeedback training for children with bladder-sphincter incoordination. J Urol 138: 1113-1115.

59. van Gool JD, Vijverberg MA, Messer AP, Elzinga-Plomp A, de Jong TP, et al (1992) Functional daytime incontinence: non-pharmacological treatment Scand J Urol Nephrol Suppl 141: 93-103.

60. Kjolseth D, Knudsen LM, Madsen B, Norgaard JP, Djurhuus JC, et al. (1993) Urodynamic biofeedback training for children with bladder-sphincter dyscoordination during voiding Neurourol Urodyn 12: 211-221.

61. Vijverberg MA, Elzinga-Plomp A, Messer AP, van Gool JD, de Jong TP, et al. (1997) Bladder rehabilitation, the effect of a cognitive training programme on urge incontinence Eur Urol; 31: 68-72.

62. Combs AJ, Glassberg AD, Gerdes D, Horowitz M (1998) Biofeedback therapy for children with dysfunctional voiding. Urology 52: 312-315.

63. De Paepe H, Renson C, Van Laecke E, Raes A, Vande Walle J, et al. (2000) Pelvic-floor therapy and toilet training in young children with dysfunctional voiding and obstipation. BJU Int 85: 889-893.

64. De Jong TP, Klijn AJ, Vijverberg M, de Kort, Van Empelen, et al. (2007) Effect of $\mathrm{BF}$ training on paradoxical PF movement in children with dysfunctional voiding. Uology 70: 790-793.

65. Groen LA, Hoebeke P, Loret N, Van Praet C, Van Laecke E, et al. (2012) Sacra neuromodulation with an implantable pulse generator in children with lower urinary tract symptoms: 15-year experience. J Urol 188: 1313-1317.

66. Gladh G, Persson D, Mattsson S, Lindstrom S (2000) Voiding pattern in healthy newborns. Neurourol Urodyn 19: 177-184.

67. Hoebeke P, Van Laecke E, Everaert K, Renson C, De Paepe H, et al. (2001) Transcutaneous neuromodulation for the urge syndrome in children: a pilot study. J Urol 166: 2416-2419.

68. Hagstroem S, Mahler B, Madsen B, Djurhuus JC, Rittig S, et al. (2009) Transcutaneous electrical nerve stimulation for refractory daytime urinary urge incontinence. J Urol 182: 2072-2078.

69. Wennergren HM, Oberg BE and Sandstedt P (1991) The importance of leg support for relaxation of the pelvic floor muscles. A surface electromyograph study in healthy girls. Scand J Urol Nephrol 25: 205-213.

70. Khen-Dunlop N, Van Egroo A, Bouteiller C, Biserte J, Besson R, et al. (2006) Biofeedback treatment in the treatment of bladder overactivity, VUR and UTI. J Pediatr Urol 2: 424-429.

71. Neumann PZ, DeDomenico IJ, Nogrady MB (1973) Constipation and urinary tract infection. Pediatrics 52: 241-245.

72. O'Regan S, Schick E, Hamburger B, Yazbeck S (1986) Constipation associated with vesicoureteral reflux. Urology; 28: 394-396. 